\title{
REFORM OF THE RULES FOR THE RISING SEAS
}

\author{
Catherine Iorns*
}

New Zealand's existing law and policy is not adequate to provide for appropriate adaptation to the effects of climate change. There have been widespread calls for law reform, particularly to the laws affecting local government decision-making on the adoption of climate adaptation mechanisms, such as the Resource Management Act 1991 (RMA). The author is one researcher who has identified the need for law reform in this area, focusing on the (in)ability of the RMA to deal with the adaptation necessary to handle the expected effects of sea-level rise. In July 2020 an independent Resource Management Review Panel (the Randerson panel) recommended replacing the current Resource Management Act with a completely new resource management system and suite of laws. One of the topics addressed in the Panel's 531-page report is law reform for climate adaptation. The Panel recommended the adoption of a separate Climate Adaptation and Managed Retreat Act to enable better decision-making processes and results. The government has adopted the Panel's recommendations and is in the process of drafting legislation to implement them. This article addresses how well the proposed reforms address the specific needs for reform identified in the author's prior work on this topic.

\section{INTRODUCTION}

It is increasingly commented on how vulnerable Aotearoa New Zealand is to natural disasters; this is now being expanded to include climate change impacts. For example, New Zealand is already the third most vulnerable country to natural disasters as a percentage of GDP before climate change impacts are taken into account. ${ }^{1}$ Sea-level rise due to climate change will increase this vulnerability - even a small amount of sea-level rise will substantially increase damage from

* Professor of Law at Te Herenga Waka | Victoria University of Wellington. Prof Iorns has undertaken research for the Deep South National Science Challenge pursuant to their Impacts and Implications Programme; see "Sea level rise, housing and insurance: Liability and compensation" Deep South National Science Challenge <deepsouthchallenge.co.nz>. The material for this article was produced through work undertaken pursuant to funding from the Deep South National Science Challenge. The views expressed here are those of the author.

1 Earthquake Commission "Briefing to the Incoming Minister Responsible for the Earthquake Commission" (October 2017) at 16 (obtained under Official Information Act 1982). 
flooding, storm surges and landslips. ${ }^{2}$ Some locations have already become uninhabitable, either due to sudden-onset disasters or a series of smaller events that accumulate to large losses, with coastal residents forced to relocate. ${ }^{3}$ Retreating shorelines and associated coastal hazard risks are forcing local authorities to reconsider the appropriateness of development in coastal areas.

Unfortunately, providing for the necessary adaptation to these coastal hazards is not easily achieved under existing laws and policies. Various researchers have separately identified that New Zealand's existing law and policy is not adequate to provide for appropriate adaptation to the effects of climate change, focusing on the effects of sea-level rise in particular. For example, in 2017 Boston and Lawrence argued for significant reform to adopt a national mechanism to fund the costs of climate adaptation nationally and share them, both intragenerationally and inter-generationally. ${ }^{4}$ The Climate Change Adaptation Technical Working Group recognised the need for proactive planning, and improvements for leadership, funding, capability and capacity building, and information to support decision-making. ${ }^{5}$ The Productivity Commission's report on local government funding stated that a national legal framework for climate change adaptation was urgently required and stressed the need for central government funding for adaptation measures. ${ }^{6}$ Under the umbrella of New Zealand's National Science Challenges, more detailed research has been conducted into the operation and evaluation of laws relating to Earthquake Commission (EQC) insurance, into adaptation decision-making and options under the Resource Management Act, into managed retreat and other ways of dealing with existing uses, and on the overall equity of the sharing of risks. ${ }^{7}$ All of the recommendations

2 Parliamentary Commissioner for the Environment Preparing New Zealand for rising seas: Certainty and Uncertainty (November 2015).

3 Catherine Iorns, Vanessa James and Patrick Gerard "Sea Level Rise and Local Government: Policy gaps and opportunities"(2020) 16 PQ 62.

4 Jonathan Boston and Judy Lawrence The Case for New Climate Change Adaptation Funding Instruments (Institute for Governance and Policy Studies, Working Paper 17/05, August 2017). See also Jonathan Boston and Judy Lawrence "Funding climate change adaptation: The case for a new policy framework" (2020) 14 PQ 40.

5 Climate Change Adaptation Technical Working Group Adapting to Climate Change in New Zealand: Recommendations (Ministry for the Environment, May 2018) [CCATWG].

6 New Zealand Productivity Commission Local government funding and financing: Final Report (November 2019).

7 Catherine Iorns, Vanessa James and Patrick Gerard The Extent of EQC liability for damage associated with sea-level rise (Deep South National Science Challenge, July 2019); Catherine Iorns and Jesse Watts Adaptation to Sea-Level Rise: Local Government Liability Issues (Deep South National Science Challenge, July 2019); Ben France-Hudson, Emily Grace and Margaret Kilvington Reducing risk through the management of existing uses: Tensions under the RMA (Institute of Geological and Nuclear Sciences, Science Report 2019/55, August 2019); and Elisabeth Ellis How Should the Risks of Sea-Level Rise be Shared? (Deep South National Science Challenge, 2019). 
focus on the need for better decision-making rules, standards and processes for adaptation to sealevel rise in Aotearoa.

In 2019, the New Zealand government commissioned an independent review of the Resource Management Act by a Resource Management Review Panel, chaired by Hon Tony Randerson, QC (frequently referred to as the Randerson Panel). The Panel's Terms of Reference included increasing New Zealand's resilience to manage climate change risks, enabling decision-making that can better reflect the needs and interests of the wider community including those of future generations, and ensuring that the RMA aligns with the government's other work and institutions responding to climate change. In June 2020 the Panel produced an extensive 531-page report that recommended comprehensive law reform, involving replacement of the current Resource Management Act with three separate pieces of legislation:

(1) a Natural and Built Environments Act (NBEA), addressing the development and protection of our natural environment, with more effective protection of natural environmental limits and more mandatory national goals, guidelines, standards and rules;

(2) a Strategic Planning Act, to address uses of land and the coastal marine area across the country in a planned and more managed way; and

(3) a Managed Retreat and Climate Change Adaptation Act, to provide legal rules pertaining to the specific complexities of climate adaptation that might differ from other situations, and to provide for a long-term funding mechanism to minimise costs and more equitably share the burden of those costs both across communities and over time.

In February 2021, the government announced that it would proceed with reform of the RMA in line with the Panel's recommendations, and it is currently in the process of developing the legislation. The signalled drafting process included the release of an exposure draft of the Natural and Built Environments Bill (NBEB) in June 2021 to enable a select committee to consider the draft before its final Bill format. It is intended to introduce the NBEB and Strategic Planning Bill to Parliament by early 2022. It has been stated that public consultation on adaptation policy will occur at the end of 2021, although this policy would be developed closely with the other proposed legislation so that "linkages between the proposed pieces of legislation are maintained". ${ }^{8}$ The proposed Climate Change Adaptation Bill would be drafted and introduced to Parliament in 2022.

This article considers the reform proposals in light of the previously identified shortcomings of the New Zealand law. It first summarises the inadequacies of the RMA process for adoption

8 Minister for Climate Change "Adaptation legislation - proposed timelines and process" (9 December 2020) CBC-20-SUB-0121. 
of climate adaptation measures as identified by the existing research; it next addresses the reforms that have been proposed in relation to climate adaptation; and finally comments on how well the reform proposals appear to meet the needs identified for the adoption of appropriate climate adaptation measures in Aotearoa New Zealand. It focuses on adaptation to sea-level rise as that has been a large focus of research work to date, although it is recognised that inland flooding poses perhaps the greatest climate hazard risk to New Zealand. ${ }^{9}$

\section{OUR PREVIOUS DEEP SOUTH WORK}

\section{A Adaptation Decisions and Measures}

Before current or proposed laws are assessed in terms of being fit for purpose, one needs to know what the purpose is: namely, the kinds of decisions that need to be made in order to adapt to sea-level rise. Local authorities will first need to be undertaking detailed assessments of the hazards and risks posed by climate change, including from sea-level rise. For example, they would need a scientific assessment of the likely sea-level movements along their coastlines, and of what land within their jurisdiction would be inundated to what extent at differing sea levels. Ratepayers and other residents will need to be informed of these hazards and risks, and future ratepayers and residents should also be able to find out about these risks. It is best if such information can be officially notified, such as on the Land Information Memorandum (LIM) for a property; therefore, decisions will need to be made on how best to do that. Local authorities will then need to decide - presumably in conjunction with their communities - what policies and plans to adopt so as to adapt to the risks and prevent the hazards from adversely affecting at least people and property. (While it would also be hoped that attention will also be paid to species and other aspects of nature that will be at risk from sea-level rise inundation, I note that the focus on the adequacy of laws to date has been on adaptation measures in order to better protect human and built environments.)

Decisions will have to be made about what kinds of new developments should be allowed in hazardous areas, whether through determining activity status in a plan or by adopting policies in relation to the granting of resource consents and the conditions under which they might be granted. This is particularly relevant for housing subdivisions on the coast and the infrastructure needed to support them, given the explicit goals of increasing housing and the widespread attraction of living near the coast.

Decisions will also need to be made about what to do about existing uses that will be threatened by rising seas. Choices will need to be made as to options for protection, if only to

9 See Ryan Paulik and others Coastal Flooding Exposure Under Future Sea Level Rise for New Zealand (NIWA and Deep South National Science Challenge, March 2019); and Ryan Paulik, Heather Craig, and Daniel Collins New Zealand Fluvial and Pluvial Flood Exposure (NIWA and Deep South National Science Challenge, June 2019). 
delay the eventuation of coastal hazard risks. Such protection options can involve constructing hard structures, such as sea walls and raising buildings, or nature-based solutions, such as through planting and land and water contouring. The hardest choices will concern whether particular housing or other developments should be abandoned and/or withdrawn from the coast in order to reduce the risk of hazards to life and property. Any need to retreat from the hazard will require decisions to be made on where to relocate to as well as how to manage it. All adaptation decisions raise issues of cost and who must bear it, but the most fraught are when a local authority attempts to implement a decision on adaptation measures that the residents involved do not support, especially if it involves the residents giving up their houses before they feel the need to move. Such situations will require robust decision-making processes, may require strong powers to change land uses, and may require resourcing to enable relocation of existing uses.

\section{B Current Law and its Need for Reform}

Helpfully, there is a range of legal tools that currently enable local authorities to make some suitable adaptation decisions, including preventing new development in hazardous coastal areas. For example, using plans, hazards can be identified in a district or region using zones and overlays. The RMA enables local authorities to limit new development in hazardous areas, including by specifying activity status, and to impose some conditions on any development that is approved. For example, s 106 of the RMA enables local authorities to decline new subdivision consent applications if there is a significant risk from natural hazards affecting the land in question. Resource consents can be denied for similar reasons or conditions could be imposed to enable future adaptation.

A key document is the NZ Coastal Policy Statement, that requires councils to avoid increasing risks from coastal hazards, and to take a precautionary approach to them. The Department of Conservation has released additional guidance on how to apply the coastal policy statement to climate adaptation matters, and the Ministry for the Environment has released a lengthy detailed guidance document on adopting coastal climate adaptation measures. ${ }^{10}$ This Ministry for the Environment Guidance includes suggestions for what types of structures and development should be allowed on land at different heights above current sea-level, as well as suggestions for community consultation procedures to enable future planning to be undertaken. The Climate Change Adaptation Technical Working Group (CCATWG) provides recommendations to the Government about possible pathways for dealing with climate change, particularly in respect of processes to use to choose adaptation mechanisms. ${ }^{11}$ The CCATWG has recommended review and reform of the RMA in order to better enable local government's ability to undertake

10 Department of Conservation NZCPS 2010 guidance note: Coastal Hazards; and Ministry for the Environment Coastal Hazards and Climate Change: Guidance for Local Government (December 2017).

11 CCATWG, above $\mathrm{n} 5$. 
adaptation. ${ }^{12}$ However, with the existence of these various documents, a strong Coastal Policy Statement and extensive guidance under it, at least councils do have some tools that enable them to act.

For example, the existing RMA processes can be used to decide whether to allow new development on coastal hazard risk areas and if so, of what types and under what conditions. Under the RMA local authorities can decide whether to protect existing development, such as through building hard protection structures like seawalls and/or develop nature-based solutions. Other legislation, such as the Local Government Act, enables local authorities to consult communities on how the community should adapt to increasing coastal hazards and whether to build such structures or retreat from the coast (or both, at different times). Finally, there are more operational mechanisms that can be adopted, such as putting sea-level rise and other coastal hazard information on property LIMs. ${ }^{13}$

However, despite the availability of such tools, communities and their local authorities are being very slow to adopt sea-level rise coastal hazard adaptation mechanisms, and application of the NZCPS in practice has not led to a consistent approach in the courts for all aspects of new development. Research undertaken into the legal and policy framework has identified many barriers to good decision-making in this area. These barriers include political pressures, lack of resourcing, actual and perceived fears of legal liability, ${ }^{14}$ and the legal system being based on inappropriate fixed legal instruments and entitlements that local authorities work within. ${ }^{15} \mathrm{~A}$ summary of the barriers and recommendations for reform is provided here; for more explanation in detail, please see the reports themselves.

12 These recommendations include: giving local government a robust mandate to act on climate change under the Act; ensuring that legislation puts climate adaptation ahead of other needs such as housing availability; aligning hazard and disaster risk reduction and climate adaptation policies; aligning land use, freshwater use and consents for subdivisions under the RMA and the Building Code. See CCATWG, above $n$, at 33-34.

13 Local authorities are required to put all information that they hold about a property on the LIM, including about any hazards that might affect it: s 44A Local Government Official Information and Meetings Act 1987. Weir v Kapiti Coast District Council [2013] NZHC 3522 and [2015] NZHC 43 held that local authorities are required to provide such information to current and prospective landowners via the LIM even if it is created at a regional rather than a site-specific scale; the key is to explain it sufficiently clearly to readers of the LIM.

14 See for example Catherine Iorns, Vanessa James and Patrick Gerard Sea Level Rise and Local Government: Policy gaps and opportunities (Deep South National Science Challenge, July 2019); and Catherine Iorns, Vanessa James and Patrick Gerard "Sea Level Rise and Local Government: policy gaps and opportunities" (2020) 16 PQ 62.

15 Iorns and Watts, above n 6. See also France-Hudson and others, above n 6. 


\section{Liability}

One of the biggest barriers to local authority action is the fear of being sued by ratepayers who disagree with the action chosen. This can impose litigation costs even if a court upholds the authority's actions with additional financial penalties if it does not. Costs are not limited to monetary costs but include time, delays and the risk that other ratepayers will take similar actions. The Australian Productivity Commission identified fear of liability as a key barrier to adoption of adaptation mechanisms in Australia. ${ }^{16}$ Researchers echoed this concern, finding that for "'most coastal councils in New South Wales,' the liability issue was now the "'single most important issue. It is the only thing on the agenda."'17 The Australian Productivity Commission recommended providing central government guidance to reduce council discretion and thus scope for challenge on what might be the most appropriate government action. ${ }^{18}$

These findings and recommendations were echoed in our survey of New Zealand local authorities, with fears of liability and lack of central guidance being commonly identified as hindrances to action. ${ }^{19}$ It has been noted that the Building Act 2004 and the RMA create two sets of inconsistent standards, with the Building Act allowing landowners to develop in high-risk areas of existing titles with minimal deterrence, and the RMA creating overly litigious processes by conferring rights of appeal on a wide range of people. ${ }^{20}$

If communities are to adapt to current and future coastal hazards, law reform will need to try and provide much greater clarity on the standards to be applied and on the powers and obligations of decision-makers. The Building Act 2004 also has a liability shield for some decisions under that Act; this could be considered for some climate adaptation decisions.

\section{New development}

With respect to new development, the problem identified is less about finding new legal and policy solutions, and more about getting local government to implement restrictions using powers that they already have. Yet even then, some of the existing standards could be made clearer and more certain so as to leave less room for challenge. For example, it was mentioned above that $\mathrm{s}$ 106 of the RMA enables local authorities to decline new subdivision consent applications if there is a significant risk from natural hazards. The drawback is that when councils use it, legal

16 Australian Government Productivity Commission Barriers to Effective Climate Change Adaptation (No 59, 19 September 2012) at 166.

17 Jacqueline Peel and Hari M Osofsky "Sue to Adapt?" (2015) 99 Minn L Rev 2177 at 2238.

18 Australian Government Productivity Commission, above n 16 at 169.

19 Iorns, James and Gerard (2019), above n 14; and Iorns, James and Gerard (2020), above n 14.

20 Iorns, James and Gerard (2019), above n 14, at 31. 
challenges often follow. ${ }^{21}$ Even where councils' decisions have been upheld by courts, standards may appear uncertain enough on their face that they invite challenge. For example, Carter Holt Harvey challenged a declined consent for subdivision on a coastal spit with argument over whether the risk from future sea level rise-induced flooding was "significant". ${ }^{22}$

Local authorities can use planning tools, such as activity status, to encourage and discourage activities in different areas. However, the RMA makes it hard to adopt prohibited activity status with the extra hurdle of requiring it to be the most appropriate option. ${ }^{23}$ This requirement needs to be relaxed in order to more easily enable local authorities to prohibit certain types of new developments in coastal hazard zones. The evaluation of proposed plan provisions should also be required to apply the precautionary principle; we recommended that s 32 of the RMA should be amended to include such an explicit direction.

Even with a strong New Zealand Coastal Policy Statement (NZCPS), coastal subdivisions for residential housing have been approved since it came into force. For example, NZCPS Policy 25 directs decision makers to "avoid" new development or redevelopment in hazardous areas, and Objective 5 mandates the use of a precautionary approach. Yet coastal subdivisions have still been approved, even though provision for future retreat has sometimes been made. ${ }^{24}$ While it looks like an approach founded upon a landowner's voluntary assumption of risk is untenable under the NZCPS, such arguments are still made. And, in relation to consents, it is not clear to what extent future retreat can be planned for when allowing new development, such as through including conditions for relocating buildings when coastal hazard trigger points are reached.

In coastal hazard risk areas, many local authorities are under pressure from their communities to undertake new coastal protection works. Although the authorities are not legally required to undertake new coastal protection works, confusion about this remains and political pressures have often meant they have been adopted, even if only as a short-term solution. ${ }^{25}$ Moreover, once built, such structures currently need to be maintained. Local authorities may have opened themselves up to future liabilities by making these decisions.

21 Iorns and Watts, above $\mathrm{n}$ 7, at 116-123 and 132-144.

22 Carter Holt Harvey HBU Ltd v Tasman District Council [2013] NZEnvC 25. This case is discussed in Iorns and Watts, above $\mathrm{n} 7$, at 135-144.

23 Resource Management Act 1991, s 32: discussed in Iorns and Watts, above n 7, at 123-127.

24 See for example Mahanga E Tu Inc v Hawkes Bay Regional Council and Wairoa District Council [2014] NZEnvC 83.

25 See Iorns and Watts, above n 7, at 161 for an example of political intervention that allowed a maladaptive coastal protection structure at Waihi Beach. 


\section{Changing existing uses}

There is currently no legal mechanism specifically designed to allow managed retreat from coastal hazards. ${ }^{26}$ Indeed, the RMA protects existing lawful uses against changes in district planning rules. This means that an activity that is in breach of current district planning rules may continue, provided it was lawful at the time it was established. ${ }^{27}$ Such "perpetual" land use rights prevent the extinguishment of existing uses that is necessary in order to move those uses out of hazard risk areas. The inability for local authorities to effectively extinguish such existing use rights is a key barrier to implementing managed retreat. A key reform necessary for managed retreat would be to remove such $\mathrm{s} 10$ protections for adaptation purposes.

It has been suggested that s 10(4)(a) of the RMA might allow a regional council to extinguish existing use rights by changing regional plan rules. However, this may not be a valid interpretation of the law, and it will likely be argued in court if used. Legal clarity on how existing uses may be extinguished and who may do it is essential. ${ }^{28}$ Further, any compensation for such extinguishment of existing use rights needs to be clarified. It is possible that the removal of residential use rights will be deemed as rendering the land "incapable of reasonable use" under s 85 of the RMA, meaning landowners would be eligible for compensation. Section 85 applications are likely to become more common if councils remove existing residential use rights. ${ }^{29}$ Explicit clarification of compensation entitlements is essential, or else they will end up being dragged out in court.

An additional helpful tool would be the ability for local authorities to review conditions of an existing consent in a wider range of circumstances. While s 128 of the Resource Management Act 1991 allows this in some circumstances, we considered it is unlikely to be available in practice to support managed retreat. ${ }^{30}$

The Local Government Act 2002 has also been identified as making infrastructure and service withdrawal difficult, even when it is required for the purposes of adaptation to sea-level rise. ${ }^{31}$

Overall, it is clear that any effective policy for addressing existing use rights is likely to require new legal measures to be established. Local authorities themselves have called for

26 Iorns and Watts, above $\mathrm{n} 7$, at 182 .

27 Resource Management Act, s 10; See also Iorns and Watts, above n 7, at 182-193 for a discussion of the legal implications of this section.

28 Iorns and Watts, above n 7, at 185-191.

29 It is noted that an expanded range of remedies under s 85 became available as a result of the 2017 amendment to the RMA.

30 Iorns and Watts, above n 7, at 191-193.

31 Iorns, James and Gerard (2019), above n 14, at 31. 
stronger decision-making powers, with some comparatively radical proposals such as the ability to "red-zone" risk-prone areas and make non-contestable decisions in certain circumstances. ${ }^{32}$

\section{Operational matters}

Even with the right rules and policies, operational matters will be key to effective climate adaptation. As councils have already identified: ${ }^{33}$

We recognise the ongoing effects of climate change will vary considerably across New Zealand, as will different communities' levels of understanding, attitudes towards the climate change and preferred courses of action. [...] For any traction to be achieved central government must provide guidance, incentives, and tangible resources for local government to start implementing climate change adaptation.

A key research finding is that central government ought to cover a greater share of the costs of information creation and dissemination because of the clear resource constraints upon local government. ${ }^{34}$

Another key finding is that effective adaptation will require national consistency, such as through rules, guidance and material assistance. Despite the existence of some government guidance on climate adaptation, national consistency does not yet exist: ${ }^{35}$

While local government responsiveness to the effects of sea-level rise is improving, there is still considerable variability between organisations, particularly in assessment of risk exposure, level of expertise and maturity of thinking within organisations, and practical responses.

In addition to the legal and practical barriers such as funding that have been identified above, political barriers result in desires to leave the hard decisions to someone else later: ${ }^{36}$

Our political cycle makes it very easy for decision makers to kick the can down the road. Although the trend (climate change) seems apparent, the likelihood of something cataclysmic occurring in the next three years remains small, so [they] can avoid and ignore the need for a tough decision.

\section{Summary}

Overall, the current planning paradigm is unsuited to dealing with the problems posed by existing use rights in hazardous areas. Under the current system of devolved planning, paired with

32 At 29.

33 Iorns, James, Gerard (2020), above n 14, at 66.

34 Iorns and Watts, above n 7, at 191-193.

35 Iorns, James and Gerard (2019), above n 14, at 5.

36 Iorns, James and Gerard (2020), above n 14, at 66. 
broad guidelines rather than prescriptive rules, councils find it difficult to adopt the necessary measures in practice. Reasons for this include: the political pressures faced by local governments, the lack of resourcing, a system based on fixed instruments, and the actual and perceived fear of legal liability. For these reasons, greater direction is required from higher levels of government, even if this breaches the principle of subsidiarity. In other words, the system needs to be inverted. Rather than flexible policy statements, we need firm directives from central government about the content of consents - namely, that the content of consents needs to be flexible rather than fixed. Furthermore, we need flexible instruments to apply to existing developments, in addition to instruments providing more information about potential hazards and risks.

\section{Matters Identified in Other Reports: Insurance and Treaty of Waitangi}

As well as the many matters discussed above arising from our report on local government liability, several matters for attention and/or reform were identified in our other reports. For example, we identified that EQC compensation was not currently available to assist with proactive adaptation to coastal hazard risks. ${ }^{37} \mathrm{EQC}$ provides insurance-based compensation designed to achieve replacement, and only once a disaster event and the relevant damage had occurred or if it is "imminent". This does not apply to known risks further into the future, such as risks of coastal hazards due to sea-level rise. When private insurance becomes unavailable as coastal hazard risks become more certain, residents may end up needing to relocate but without the financial resources to do so.

We did not suggest that EQC needs to be modified to provide such an adaptation mechanism, but merely identified that it cannot currently assist with a proactive adaptation program. If we feel as a society that people should be encouraged to adapt in order to avoid future climate-related hazards, before the hazards eventuate and cause damage, then we will likely need to devise a program of financial assistance in order to assist such adaptation.

My 2019 report on Te Tiriti o Waitangi/the Treaty of Waitangi considerations relevant to climate adaptation identified a number of shortcomings of the current system under the RMA. ${ }^{38}$ The primary reason is that the RMA is not Treaty compliant: the Waitangi Tribunal has found that provisions of the RMA breach the principles of the Treaty in respect of both process and substance. In relation to process, most decision-making under the RMA does not respect Treaty principles with the level and type of participation by iwi or Māori in decision-making under the Act. In relation to substance, the principles to guide decision-making do not require protection of interests that might be protected by art 2 of the Treaty, for example. Moreover, there are many

37 Iorns, James and Gerard, above n 7.

38 Catherine Iorns Treaty of Waitangi duties relating to adaptation to coastal hazards from sea-level rise (Deep South National Science Challenge, July 2019). 
examples of RMA decisions violating such substantive protection, such as in relation to resource consents: Māori interests in land and resources are frequently outweighed by other considerations under the Act, particularly commercial and development interests of non-Māori. My 2019 report thus made several suggestions for what Treaty obligations might require of climate adaptation decision-making, so as to better ensure that Māori do not lose ties to ancestral lands and can maintain their relationships with the coastal environment, while recognising their authority to preferably control but at least share in making decisions over those assets. Because of the extent of these recommendations, they are not able to be canvassed in this short article, nor can an assessment be made of how well the Randerson reform proposals meet those recommendations; instead, these matters need a separate article. It is thus only briefly addressed in section III, E below.

\section{RESOURCE MANAGEMENT REVIEW PANEL REPORT}

The Resource Management Review Panel Report proposes a comprehensive reform package with underlying principles that are different from those of the current legislative regime, plus significant reforms designed to better enable adaptation to the effects of climate change. In summary, the proposals appear to address all of the main shortcomings identified above in relation to the adoption of better climate adaptation measures. ${ }^{39}$ Significantly, the proposals even include some more radical alterations to the protection of existing property rights and related measures to enable managed retreat from hazard risks. However, despite its overall size and breadth, only one chapter of 26 pages is devoted to "Climate change and natural hazards", and this chapter addresses both mitigation and adaptation options. Thus, any overall assessment has to note that, while it looks like all relevant matters will be addressed, the success will come down to the detail included in any eventual rules. As is always the case with law reform, the devil will be in the detail, in how much the words and provisions that are chosen achieve the reform goals identified. The following sections attempt to summarise the recommendations and relate them to the matters identified earlier for reform, discussing how well they appear to meet the needs identified.

\section{A Identifying the Issues}

The Panel Report identifies at a broad level all the significant issues that have caused insufficient adoption of appropriate climate adaptation measures. It notes the low priority of consideration of the effects of climate change in pt 2 of the RMA (as an "other matter" in s 7), as well as a lack of a proper framework within the RMA for considering risk. The effects-based approach of the RMA does not lend itself towards a proactive risk management approach. ${ }^{40}$ The

39 Resource Management Review Panel New Directions for Resource Management in New Zealand: Report of the Resource Management Review Panel (July 2020).

40 At 171. 
Panel identifies five problems with the RMA planning framework and two other systemic problems. All of these seven have been previously identified in the research to date.

1."A lack of national direction and guidance from central government", including development at a national level of "science, data and information needed, as well as best-practice planning approaches". ${ }^{41}$ This has hindered local decision-makers in respect of reducing the risks of natural hazards relevant to adoption of climate adaptation measures. The lack of national direction was also identified as producing "additional litigation" as councils tried to formulate their plans and policies without clear standards. ${ }^{42}$

2. "Difficulties addressing contentious issues in the development of local plans": the Panel identifies that uncertainties about the science and the hazard risks, and best planning approaches to them, have led to litigation and fears of it that have paralysed adaptation planning and other measures. ${ }^{43}$ One of the key criticisms of council plan-making was that it was "prone to litigation". 44

3. "Lack of clarity in regard to roles and responsibilities" between regional councils and territorial authorities, both in relation to powers and costs. ${ }^{45}$

4. "Planning for managed retreat": the Panel reiterates the difficulty that local authorities have in adopting managed retreat in the face of the current protection for existing uses under the RMA. Chapter 5 of the Report discusses solely the status quo bias in the RMA, and identifies the need to review existing use protections under s 10 of the RMA as well as in respect of to land use consents - both modification of an original consent as well as review of consent conditions. ${ }^{46}$ The Panel also identifies the uncertainties posed by the application of the compensation provision, s 85 of the RMA, in the context of providing for climate adaptation, particularly managed retreat. ${ }^{47}$
41 At 172
42 At 196
43 At 172
44 At 226.
45 At 172
46 At 158 and 162 .
47 At 185 
5. "Particular issues in relation to risks for Māori": the Panel notes how important it will be to "consider the ability of Maori to determine how taonga and whenua are managed in response to climate change". 48

6. "Poor integration across the resource management system and particularly between the CCRA and RMA", but also the Local Government Act, such as in respect of infrastructure and long-term planning. ${ }^{49}$

7. A lack of funding is contributing to "policy inertia and uncertainty" : "the scale of response required and the ability to fund some decisions are likely to be beyond the means of local authorities". 50 "Central government will need to assist". 51

\section{B National Guidance}

As discussed above, three statutes are proposed to arise out of the reform process, only one of which is labelled as the Climate Adaptation Act. However, all three will combine to address adaptation to climate change much more effectively than the current legal regime. The most significant systemic changes are the intended prioritisation of achievement of climate adaptation, the production of national guidance, and regional spatial planning.

First, the proposed Natural and Built Environments Act adopts an extensive set of principles to help guide and interpret decision-making powers and standards under the Act. The most significant for our purposes is the explicit outcome statement in what is now $\mathrm{cl} 8$ of the Exposure Draft of the Natural and Built Environments Bill: ${ }^{52}$

8 Environmental Outcomes: To assist in achieving the purpose of this Act, the national planning framework and all plans must promote the following environmental outcomes:

(p) in relation to natural hazards and climate change, -

(i) the significant risks of both are reduced; and

(ii) the resilience of the environment to natural hazards and the effects of climate change is improved.

48 At 173.

49 At 173 and 174

50 At 174 and 175.

51 At 175 .

52 Ministry for the Environment Natural and Built Environments Bill: Parliamentary paper on the exposure draft (June 2021) at 66. 
I suggest that this is an excellent proposal. Promoting an outcome is not simply taking a matter into account or even paying it "particular regard"; it instead suggests that these outcomes be achieved. ${ }^{53}$ This leaves a lot less discretion to decision-makers to balance out reducing coastal hazard risks with economic coastal development and its associated income, for example. This produces more certainty for councils and less room for challenge by those unhappy with provision for such outcomes.

To implement this directive, it proposes a section requiring the Minister to provide national direction to "identify and prescribe: ... methods and requirements to respond to natural hazards and climate change" to meet the suggested climate risk outcomes. ${ }^{54}$ The Panel suggests the following matters for such national direction: ${ }^{55}$

- adaptation and natural hazard risk assessment methods and priorities for risk reduction

- $\quad$ specific risk information and mapping to be relied on (for example, projected sea-level rise)

- $\quad$ preference for nature-based solutions for climate change adaptation ...

- $\quad$ approaches to facilitating the adaptation of indigenous species

- $\quad$ best practices for accommodating uncertainty, for example dynamic adaptive policy pathways planning ...

- other technical specifications.

I suggest that such mandatory direction is exactly what is needed to fill some current gaps in direction to local authorities. It will remove the current difficulty with having only optional National Policy Statements under the RMA: the proposed outcomes must be provided for and the national direction to implement them must be given; they are not optional. This on its own will assist the adoption of adaptation measures by reducing litigation over the mechanisms adopted.

Additionally, more detailed guidance on climate adaptation in particular will still be necessary in the separate Climate Adaptation Act. For example, while the need to take a precautionary approach is recognised in the NBEA, ${ }^{56}$ this currently refers to the need to protect only the natural environment rather than a more proactive approach to risk management to protect the built environment in the face of climate change. I therefore suggest that guidance principles specifically tailored to climate adaptation will need to be devised for that legislation.

53 Resource Management Act, s 7.

54 Resource Management Review Panel, above n 39, at 486

55 At 181

56 See the Panel's proposed s 9(2)(g) and the Exposure Draft cl 18(g): Resource Management Review Panel, above $n 39$. 
One identified but unspecified necessity is more guidance on specific adaptation mechanisms, such as options for flexible consents and their conditions. The reference to a preference for naturebased solutions is helpful attention to one aspect of choosing adaptation mechanisms. However, there are additional specific mechanisms that could usefully be the subject of guidance. In addition to elaborating on options for consents and conditions, specific guidance on how to best represent future risk information on a LIM would be a valuable topic, as doing this in the wrong way has already resulted in one council have its sea-level rise science information ruled unacceptable and to be taken off LIMs in Kapiti. ${ }^{57}$ Perhaps such guidance on specific options could be included under "other technical specifications"; but it would be helpful to have it made clear that it would be so included, such as by including another bullet point on "specific adaptation mechanism options".

One aspect of national guidance that is signalled out for additional elaboration is that of appropriate planning processes. Adopting the right process for community decision-making is essential in this area, in order to achieve buy-in and adoption of the necessary timeframes for achieving appropriate adaptation outcomes. The Panel approves of the Ministry for the Environment guidance on the use of the Dynamic Adaptive Policy Pathways planning process. ${ }^{58}$ This process provides a way for a community to identify the best adaptation options for the future, given different scenarios and trigger points for the emergence and eventuation of coastal hazards. What the Panel's recommendation does is better provide for building adaptive management into the plan-making process and embedding such pathways in plans, thereby better enabling flexibility and responsiveness when predicted hazards do arise.

Finally on national guidance, I applaud the attention to be given to "approaches to facilitating the adaptation of indigenous species", listed above. ${ }^{59}$ While this was not a focus of our previous research, it has been lacking from the national debate on adaptation to climate change. It is essential that adaptation options be identified for species and other aspects of nature that will be at risk from the effects of climate change, and it is excellent to see it included in the Panel's priorities for national direction.

Another appropriate process recommendation from the Panel is the clarification of roles for climate adaptation and hazard risk reduction, specifying which level of government is most appropriate for the different tasks. This is a matter that has already been identified as not clear under the RMA - for example, whether or not regional authorities can enable managed retreat through land use changes. The Panel helpfully also suggests that such responsibilities should be

57 Weir v Kapiti Coast District Council, above n 13.

58 Resource Management Review Panel, above n 39, at 182

59 At 181 
made explicit in the Local Government Act, which assists with integration of climate adaptation with infrastructure, transport, and long-term plans. ${ }^{60}$

The second proposed piece of legislation - the Strategic Planning Act - proposes to "provide a framework for mandatory regional spatial planning for both land and the coastal marine area". ${ }^{61}$ Such "[r]egional spatial strategies should set long-term objectives for urban growth and land use change, responding to climate change, and identifying areas inappropriate to develop". ${ }^{62}$ Spatial planning strategies will explicitly address adaptation through identifying within each region "areas that may be affected by climate change or other natural hazards, and measures that might be necessary to address such issues". ${ }^{63}$ The Panel suggests that regional spatial plans will also: ${ }^{64}$

improve the alignment between the Natural and Built Environments Act and the CCRA [Climate

Change Response Act 2002], including through consideration of national adaptation plans in regional spatial strategies and regional combined plans.

The significance of this kind of planning is that it reduces post-hoc emergency-style decisionmaking in response to coastal hazard risks in the future, and encourages proactive adaptation decision-making now. Especially with the integrated responsibilities - such as in respect of infrastructure, transport, long-term plans and the national adaptation planning under the Climate Change Response Act - competing priorities can all be discussed with the benefit of more time than would be had if there was an eventuated risk requiring immediate action. It is also likely to produce a wider array of future adaptation options by not closing off options that might result from approving developments now on sites that would have been better suited to another choice in the future. Hopefully, this can also provide for calmer and less politically fraught discussions, leading to more socially accepted adaptation mechanisms, with thus less risk of maladaptation.

The final recommendation from the Panel in respect of national guidance for climate adaptation is the provision of a: ${ }^{65}$

centralised pool of expertise to assist local government with policy development for climate change adaptation, including the ability to apply experience, broker partnerships, and supply templates, information and other common resources.

60 At 183

61 At 155

62 At 155

63 At 28 and 143.

64 At 29.

65 At 190. 
Some of this assistance will come through the national direction mentioned above on environmental management and land use regulation; however, the rest will be matters for implementation assistance outside of that. This recommendation addresses comments that have been made by local and regional governments consistently over the last few years, and that were reflected in our survey of local government. ${ }^{66}$ I note that it is possible that this central pool of expertise could provide guidance on specific adaptation mechanism options, and thereby obviate the need for it to be included in the list of mandatory matters for national direction.

\section{Existing Uses}

The Panel addresses head-on the legal mechanisms needed in order to enable modification of existing uses and achieve managed retreat. It suggests that central government should have the power through national direction "to modify or extinguishing existing use protections and consented activities ... This will enable central government to address these issues when a centrally driven solution is thought necessary". ${ }^{67}$ The Panel also suggests that both regional and territorial authorities should have increased powers to review and modify consents and conditions, and that territorial authorities should be able to "modify or extinguish established land uses" for purposes of adapting to natural hazard risks. ${ }^{68}$

It is explicitly identified that existing use protections currently protected under s 10 of the RMA will need to be amended. This removal of existing use protection under s 10 is significant because it is such a major change from the current system, and it is only recommended in two situations, one of which is "where necessary to adapt to the effects of climate change or to reduce risks from natural hazards". 69

The Panel also identifies that the ability to challenge plans and obtain compensation under $\mathrm{s}$ 85 will need to "be reviewed". ${ }^{70}$ While the panel suggested in its Chapter 5 on the status quo bias that s 85 needed to be "reviewed more generally", in the context of managed retreat and natural hazards it recommends that it be revised for their proposed separate legislation on adaptation. ${ }^{71}$

While all of these three aspects are essential in order to address existing uses for effective climate adaptation, they go against strongly held views about personal property rights in Aotearoa; so it is significant that the Panel identified these issues. And it is even more significant

66 Iorns, James and Gerard (2019) and (2020), above n 14.

67 Resource Management Review Panel, above n 39, at 186

68 At 186.

69 At 162.

70 At 187.

71 At 187 
that they then recommended removing such existing use protections in order to reduce the risks of natural hazards and climate adaptation.

The Panel goes even further than these more technical matters about reviewing existing uses. The Panel identifies that the removal of existing uses in order to achieve a managed retreat from natural hazard risks is so complex and requires addressing so many different issues that there needs to be a separate statute providing for them. ${ }^{72}$ It will need to include matters relating to "funding, land acquisition, compensation, liability, and insurance, both for land owners and local authorities", as well as the maintenance of "infrastructure services in areas under threat". ${ }^{73}$

The Panel accordingly proposes that government adopt a new "Managed Retreat and Climate Change Adaptation Act" containing these matters (CCAA for short).$^{74}$ There is no draft nor detail of the provisions in this proposed CCAA; however, the main issues to be included in this new legislation are identified as: ${ }^{75}$

- a fund to support climate change adaptation and reducing risks from natural hazards, including principles for cost-minimisation and burden sharing, and cost-sharing arrangements

- $\quad$ power under the proposed Natural and Built Environments Act to modify existing land uses and consented activities

- $\quad$ power to acquire land, with potential compensation determined through specified principles rather than market-valuation

- $\quad$ power to use taxes, subsidies or other economic instruments to incentivise changes in land and resource use

- $\quad$ engagement with affected communities

- $\quad$ engagement with Māori to address cultural ties to land

- $\quad$ impacts on insurance arrangements for land owners and local authorities

- obligations on local authorities to provide infrastructure

- liability issues for local authorities

- the potential role of the Environment Court for aspects of the proposals.

Of all matters to be addressed in the Act, the Panel provides the most guidance in relation to funding and compensation. It recommends that current market valuation approaches not be used for compensation in situations of managed retreat, and that instead, the principles in the Boston and Lawrence report on managed retreat funding be adopted. ${ }^{76}$ Moreover, because we are dealing

72 At 187 and 188 .

73 At 187.

74 Climate Change Adaptation Act.

75 Resource Management Review Panel, above n 39, at 189 and 190.

76 At 189 and 190, citing Boston and Lawrence (2018), above n 4. 
with incentivising land-owner behaviour change over time, the Panel recommends the development of economic instruments such as targeted rates in addition to regulatory control. ${ }^{77}$ Addressing such solutions were outside the scope of our Deep South report on local government liabilities, but the Panel's recommendations certainly address at a general level the issues and problems that are arising under the current RMA regime in relation to compensation and threats of legal action in respect of it. How well the suggested reforms will work for actually handling managed retreat will depend on the details of the options developed,

\section{Litigation}

A final comment should be made about litigation fears. Litigation is a recurring concern of local authorities in respect of plans and consents - indeed, all aspects of the RMA process. The Panel has recognised that throughout its report, and frequently made recommendations designed to clarify the rules, establish consistency and reduce contention and litigation opportunities. As identified above (in section III, A), the Panel recognises that some of the key difficulties with the current RMA regime is the considerable amount of litigation it has produced, slowing down decision-making on plans and consents. The Panel specifically identifies some of its solutions as intended to avoid litigation through producing increased clarity about the rules, and even mentions an intention to "discourage relitigation of agreed strategic directions", for example. ${ }^{78}$

I agree that the use of national direction and guidance as proposed will significantly reduce litigation over what is allowed and what is not. Obviously, drafters can never anticipate all the fact situations that will cause questions to arise over interpretation of words in that legislation in the future. In the case of climate adaptation, that is a real issue because we are not sure exactly what will be needed by way of adaptation and what risks will eventuate. However, we have enough of an idea to know what kinds of debates have arisen over environmental and resource decision-making, and the kinds of positions we already know about give a good idea of what litigation might arise in the future. A good illustration of this is the Panel's discussion of a revised definition of "environment" in the new legislation. The Panel comments: ${ }^{79}$

It should be noted that while we consider a broad definition of the environment to be necessary within an integrated system of resource management, our proposed definition excludes reference to 'amenity values' and the 'social, economic, aesthetic, and cultural conditions' associated with aspects of the environment. These are highly subjective matters which have led to considerable uncertainty and litigation. They are also commonly relied on by submitters as an argument for protecting the status quo. Our suggested way forward is to remove these references from the definition of the environment

\footnotetext{
77 At 189 .

78 At 152 .

79 At 74 .
} 
and to require the features and characteristics that contribute to enhancing the quality of the natural and built environments to be specified in mandatory national direction.

There is no discussion of litigation specifically in relation to climate adaptation decisions, nor is there discussion of whether there should or should not be any liability shield, such as has been raised by several New Zealand councils. ${ }^{80}$ However, I suggest that the discussion above in relation to avoidance of litigation generally will apply similarly to adaptation decision-making.

\section{E Protection of Treaty Interests}

The protection of Māori interests, and particularly art 2 taonga, was a significant area of our research and of the Review Panel's recommended reforms. While this section will not review them in detail, it is worth noting that the better protection of Treaty interests is one area of the Review Panel's recommendations that appears to be addressed quite well. The Panel proposed that the new legislation comply with Treaty principles and that it contain both procedural and substantive outcomes that protect Māori interests. As a result, the Exposure Draft of the NBEB adopts the strong directive that "[a]ll persons exercising powers and performing functions under this Act must give effect to the principles of te Tiriti o Waitangi". ${ }^{81}$ It further directs in the proposed cl 8 that the planning framework and all plans must promote the following outcomes: ${ }^{82}$

(f) the relationship of iwi and hapū, and their tikanga and traditions, with their ancestral lands, water, sites, wāhi tapu, and other taonga is restored and protected;

(g) the mana and mauri of the natural environment are protected and restored;

(h) $\quad \cdots$

(i) protected customary rights are recognised.

There are also significant procedural recommendations to better uphold Treaty-compliant decision-making under the new regime. With this and the substantive outcome statements, resulting decisions will likely better uphold Māori interests, including in relation to climate adaptation decision-making.

\section{ANALYSIS}

A large number of problems have been identified with the current regime, both by my Deep South research and by the Resource Management Reform Panel, as summarised in the earlier

80 Iorns, James and Gerard (2019), above n 14, at 29.

81 Natural and Built Environments Bill Exposure Draft 2021, cl 6.

82 Clause 8. 
sections of this article. ${ }^{83}$ The Reform Panel has proposed attention to all of these aspects, at least at the overview level, even if not all have yet been addressed in the detail that will be necessary. In summary, the current proposals all appear to provide some necessary elements of the solution, even if not yet sufficient. There will certainly be a much clearer planning framework and guidance for the adoption of adaptation measures. The reforms will thus enable better planning and the evaluation of options, including risk assessments. But beyond that, not all matters were addressed.

The specific matters identified for resolution and amendment in our previous reports for the Deep South National Science Challenge fall into three categories:

- $\quad$ several are clearly addressed by the Panel and will be resolved by the proposed reforms;

- a few are not explicitly addressed but appear as if they will also be resolved; and

- $\quad$ some are not addressed at all, so whether they are resolved or not will come down to the next steps of policy development and drafting of the resulting legislation.

Overall, I suggest that the success will come down to the detail that has not yet been developed, as well as the matters that were not addressed.

An example of an implied resolution is our detailed discussion of the use of consent conditions. In order to better handle retreat from risks, local authorities need firm directives about the content of resource consents, particularly for subdivision and building, including that the content of consents needs to be flexible such as to allow for conditions to relocate buildings when coastal hazard trigger points are reached. ${ }^{84}$ While such flexible consent conditions were not specifically mentioned by the Panel, enabling future retreat and changed options were explicitly provided for. For example, the recommended Dynamic Adaptive pathways Planning is based on different future scenarios and actions that could change depending on whether pre-defined trigger points are reached. Adopting this as best practice would (arguably) necessarily entail the adoption of mechanisms that enable such changes in choices, such as flexible consent conditions and other types of flexible instruments to apply to both new and existing developments. Thus, the various different Panel recommendations made - for both the adaptation-specific provisions in the CCAA and the more general directions in the NBEA and SPA - make it look as though matters such as our recommendations on consent conditions would be included and that, therefore, such issues with the current situation would be resolved.

There are a few matters where not enough detail is provided in the report to enable an assessment of whether the legislation might meet our recommendations. One that we noted above

83 See for example, the seven categories identified by the Resource Management Reform Panel, above in section III, A of this article.

84 Iorns and Watts, above $\mathrm{n}$ 7, at 7-8; for discussion of the use of consent conditions for adaptation purposes, see 145-158. 
is that the RMA makes it hard to adopt prohibited activity status with the extra hurdle of requiring it to be the most appropriate option; we thus recommended that this be amended. In the new regime we do not know if the RMA activity status classifications will be continued. ${ }^{85}$ But if they are, thought will need to go into the detail of the drafting around their definition and the way they will function in plan-making and other local authority decision-making so as to avoid the hurdles that they can currently provide within the RMA regime.

Despite all the positive indications about effective solutions, the biggest challenge will be in actually implementing much of what is needed. This will occur particularly when dealing with changes to expectations around uses of private property, especially existing uses retreating from risks. As mentioned above, the Review Panel recommends a mix of promising principles for the handling of managed retreat, but it is light on the detail. Key to dealing with existing uses (including housing, business, and infrastructure) will be funding arrangements to enable the changes. Property losses and business disruptions, not to mention restrictions needed for the natural environment's adaptation to climate change, will cause significant stress and conflict, even with adequate finance. The Review Panel helpfully approved of the principles developed to date, such as those put forward by Judy Lawrence and Jonathan Boston. ${ }^{86}$ But so much of the detail that is still to be developed is highly controversial, and it will be extremely challenging to get widespread agreement on any options to adopt, especially where alternative funding models and options to enable managed retreat are involved. Devising a scheme for compensation for property loss will in itself be controversial and politically difficult. This still needs much more detailed attention before inclusion in a Climate Adaptation Act.

As the Minister for Climate Change has noted in 2020:87

the [Panel's] recommendations for discrete adaptation legislation are one of the least developed areas within the Report. Significant policy work is required, using the Report's recommendations as a starting point, to determine the scope and develop the detail of the proposals.

As noted above, despite its overall size and breadth, only one chapter of 26 pages is devoted to "Climate change and natural hazards", and this chapter addresses both mitigation and adaptation options. Thus, any overall assessment has to note that, while it looks like all relevant matters will be addressed, the success will come down to the detail included in any eventual rules. As is always the case with law reform, the devil will be in the detail, in how well the chosen words and provisions achieve the reform goals identified.

85 Section 32.

86 Boston and Lawrence, above $\mathrm{n} 4$.

87 Minister for Climate Change, above n 8, at [28]. 
The drafting of a new law always has to choose between certainty and flexibility in the interpretation of terms, and thus in the requirements and entitlements under the new law. There will no doubt be future legal challenges when we are dealing with matters as important and expensive as people's homes; lawyers on behalf of their clients will identify any uncertainty or terms with potential "wiggle room", and will try to push interpretations favourable to their clients. The need to discourage "NIMBY"88 litigation suggests that certainty needs to outweigh flexibility. However, the uncertainty of how future hazard risks will eventuate suggests the need to be flexible in the choice of appropriate adaptation measures. The drafting of these new laws will have to navigate both these pressures of certainty in some situations but flexibility for others, knowing that any misstep could result in maladaptation through litigation. While the litigation discussion above (section III, D) suggests that there will be a lot less litigation under the proposed legislation than there is currently, there is still a lot riding on how these RMA reforms are drafted.

Finally, I must note that there are still a number of matters relevant to effective adoption of adaptation measures that are not addressed by our Deep South reports and only minimally by the Reform Panel. For example, not enough attention has been given to date to the risks to the natural environment under climate change scenarios, such as what different species will need by way of climate adaptation (in the face of habitat or food changes, for example). Instead, most research attention and policy action has focused on the built environment. I suggest that the adoption of our human adaptation measures needs to be bounded by environmental limits so as to ensure that the adaptation measures themselves will not create greater environmental problems in the future, even while they effectively solve some short-term human adaptation problems. Such environmental limits thus need to be determined before the appropriate measures are designed and adopted. As the adoption of stronger environmental limits generally is a key design feature of the whole reform package, ${ }^{89}$ this might actually be achievable. But it will still need specific

88 NIMBY stands for "Not In My Back Yard". It is a derogatory term implying that a complaint is not always objectively justified.

89 The Review Panel proposed mandatory environmental limits to protect "biophysical aspects of the environment including freshwater, coastal water, air, soil and habitats for indigenous species": New Directions for Resource Management in New Zealand - Report of the Resource Management Review Panel: Summary and Key Recommendations (June 2020) at 3. Such limits should incorporate "a safety buffer to manage risks and uncertainty": Resource Management Review Panel, above n 39, at [61], and drafting suggestions at [129]. The government has adopted this aspect and describes environmental limits as "pivotal" to achieving the purpose of the Act: Ministry for the Environment, above n 52, at [33]; and that environmental limits will make a "key contribution" to "protecting ecological integrity" of the natural environment: Ministry for the Environment, above n 52, at [110]. I have several concerns about the limits as currently designed - their levels, who sets them and the process for setting them - but their intended function is crucial. For more detail on criticisms of the limits, see for example Environmental Law Initiative Submission on the Natural and Built Environments Bill (4 August 2021) at [8]-[56]. See also Catherine Iorns and Allan Brent "Race to the bottom in RMA reform" Stuff (online ed, New Zealand, 30 
attention as part of the drafting of the Climate Adaptation Act. This is an example of how we will need to keep in mind the various different goals in our resource management law regime or system even while we design only one part of it.

\section{CONCLUSION}

The proposed NBEA provides: ${ }^{90}$

a much-needed reset of the planning framework for climate change adaptation and natural hazard

risks. In particular, the shift to an outcomes-based approach better lends itself to planning for risk.

But it is not just the outcomes approach that is to be so sharply contrasted with the RMA regime. The use of mandatory regional spatial plans, within an overall coordinated national framework, will enable planning to occur in ways that have been prevented to date. In relation to the planning framework for climate change adaptation and natural hazards, the spatial planning will enable identification of appropriate areas for different activities and where current activities might need to change in order to reduce coastal hazard risks. Along with the use of the national standards and direction outlined here, the ability to review existing use protections, and the use of appropriate community consultation procedures to help choose future adaptation pathways, coordinated planning for climate adaptation will be enabled, and appropriate adaptation decisions will be much more likely to be made.

Overall, the recommended mandatory national planning and outcomes, coupled with guidance and other assistance for implementation, mean that there will be consistency throughout the country, as well as clearer signalling to ratepayers and prospective developers what is to be expected. With greater clarity there will be more certainty in the rules to be applied, and thus less room for legal challenge.

In early 2019 we identified in our survey of local councils that: ${ }^{91}$

If the key issues of community engagement, funding, specialist resourcing, climate adaptation decision-making for Māori land, cost apportionment and managed retreat are addressed at a national level, local authorities would be much better placed to manage the effects of sea-level rise at a local level.

The Randerson Panel's Report has indeed recommended that all of these matters be addressed at a national level. If these reforms are enacted, local government in Aotearoa will be in a much

September 2021) <www.stuff.co.nz>; and Catherine Iorns and Matthew Hall "Limits are limits in highstakes environment bill" (8 September 2021) Newsroom 〈www.newsroom.co.nz〉.

90 Resource Management Review Panel, above n 39, at 181.

91 Iorns, James and Gerard (2019), above n 14, at 5. 
better place to manage the effects of sea-level rise, as well as adaptation to climate hazards more generally.

However, much of the current proposals lacks the detail that is required to assess yet whether the reforms will actually succeed in these goals. Some of the issues with the current system are due to drafting choices of words and thresholds. There will need to be an interesting mix of certainty and flexibility in the drafting of the new law, and it is not yet clear how that will be achieved. Other issues will arise due to interrelationships with other aspects of the wider reform, such as the application of environmental limits to climate adaptation decision-making. Yet others are part of a policy suite that has yet to be determined. But of course, the most difficult will be the political differences over priorities and choices to be made, especially when the details of managed retreat and funding mechanisms are yet to be determined, and as a voter backlash to any part of this could derail the reforms. They all point to a tough road ahead. It is still a road that needs to be travelled, but travelled - if not negotiated - very carefully if we are to achieve effective adaptation to the effects of climate change in this country. 